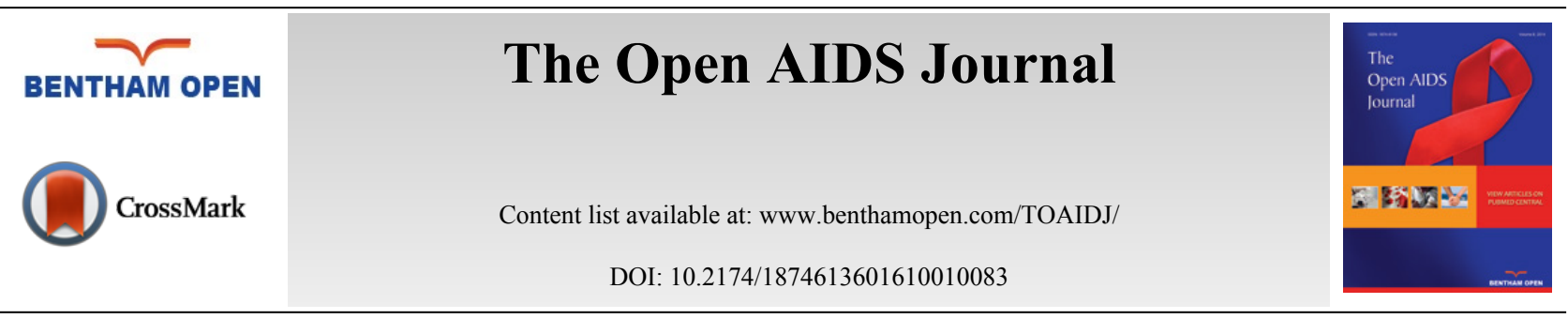

\title{
Assessing Implicit Cognition Among Patients Lost to Follow-up for HIV Care: A Preliminary Study
}

Eric Houston ${ }^{*}, 1$, Thomas Lyons ${ }^{2}$, Brenda Wolfe ${ }^{3}$, Norma Rolfsen ${ }^{4}$, Maryanne Williams ${ }^{4}$, Monique Rucker $^{3}$ and Nancy Glick ${ }^{3}$

${ }^{\text {I}}$ Department of Psychology, Illinois Institute of Technology, Chicago, IL 60616, USA

${ }^{2}$ College of Health Sciences, Chicago State University, Chicago, IL 60628, USA

${ }^{3}$ Mount Sinai Hospital Medical Center, Sinai Urban Health Institute, Chicago, IL 60608, USA

${ }^{4}$ Mercy Hospital \& Medical Center, Michael Reese Research \& Education Foundation, Chicago, IL 60616, USA

Received: January 14, 2016

Revised: February 29, 2016

Accepted: March 14, 2016

\section{Abstract:}

Objective:

While a growing body of research indicates that implicit cognitive processes play an important role in a range of health behaviors, the assessment of these impulsive, associative mental processes among patients living with HIV has received little attention. This preliminary study explored how multidimensional scaling (MDS) could be used to assess implicit cognitive processes among patients lost to follow-up for HIV care and develop interventions to improve their engagement.

\section{Method:}

The sample consisted of 33 patients who were identified as lost to follow up for HIV care at two urban hospitals. Participants were randomly assigned to either the MDS assessment program or control group. All participants underwent measures designed to gauge behavioral change intentions and treatment motivation. Assessment group participants were interviewed to determine their reactions to the assessment program.

\section{Results:}

The MDS assessment program identified cognitive processes and their relationship to treatment-related behaviors among assessment group participants. Assessment group participants reported significantly greater behavior change intentions than those in the control group ( $p=.02$; Cohen's $d=0.84$ ).

\section{Conclusion:}

MDS shows promise as a tool to identify implicit cognitive processes related to treatment-related behaviors. Assessments based on MDS could serve as the basis for patient-centered clinical interventions designed to improve treatment adherence and HIV care engagement in general.

Keywords: Antiretroviral adherence, health behavior change, health disparities, implicit cognition, motivation, patient retention, web-based technology.

\section{INTRODUCTION}

Dual process models propose that treatment adherence and other health behaviors are influenced by two distinct cognitive processes $[1,2]$. On one hand are explicit cognitive processes that are characterized by intentional reflection

* Address correspondence to this author at Department of Psychology, Illinois Institute of Technology, 3105 S. Dearborn St., Chicago, IL 60616, USA; Tel: (312) 567-5936; Fax: (312) 567-3493; Email: ehousto1@iit.edu 
and reasoning. An example of such processes would include consciously deciding to initiate antiretroviral therapy (ART) for HIV after weighing the pros and cons of pursuing such a health goal. In contrast, implicit cognitive processes are automatic and impulsive, operating out of the individual's awareness. For some patients, thoughts about treatment may be unknowingly associated with a significant other (e.g., family member, partner, medical provider), triggering mental associations that either facilitate or impede adherence. Similarly, thoughts about treatment in terms of its association with a competing goal or a specific event (e.g., desires to avoid aversive medication side effects or serostatus disclosure) may unknowingly lead to responses that negatively impact treatment behavior [3].

People living with HIV (PLH) report high rates of depressive symptoms and often experience a mix of psychosocial stressors, including stigma, poverty, and perceived discrimination [4 - 8]. Psychosocial stressors and depressive symptoms make individuals particularly vulnerable to the influence of implicit cognitive processes [9, 10]. People with major depression, for example, have an attentional bias for negatively-valenced information and interpretations [11], and this attentional bias attracts a multitude of health-compromising thoughts which affect both explicit and implicit processes. Faced with circumstances where negative cognitive material has greater salience, a depressed individual's ability to override health-compromising implicit processes through corrective, explicit processes may be overwhelmed. While ART requires adherence rates of $95 \%$ or higher for a patient to achieve immunological benefits and virologic suppression [12,13], research indicates that more than half of patients are unable to meet these stringent standards [14, 15]. Part of the problem may be implicit cognitive processes that adversely affect adherence to ART.

Assessing implicit cognitive processes is necessary to better understand how they impact self-regulatory efforts and treatment initiation among PLH. Given their hidden nature, such assessment procedures would require the use of an implicit method of inquiry [16, 17]. Multidimensional scaling [MDS; 18, 19] is an exploratory data analysis technique that can uncover implicit cognitive processes related to treatment [20]. MDS asks individual patients to provide their immediate and instinctive rating of the similarities of their own treatment-related cognitions and then uses these ratings to generate a geometric mapping of the patient's underlying cognitive processes. These mappings provide a visual depiction of how specific cognitive processes operate outside an individual's awareness to either facilitate or compromise HIV care engagement. In an MDS study where patients are not provided instructions on how to judge or determine the similarity of their thoughts in relation to various treatment behaviors, the similarity ratings are viewed as natural, unconstrained, and fueled by implicit or nonconscious criteria [20,21].

In this preliminary study, we explored the potential of using MDS to assess implicit cognitive processes among patents with poor levels of HIV care engagement. We defined care engagement as involving a range of patient activities, including presenting for care, keeping scheduled appointments, communicating and staying in contact with health providers, seeking help when needed to address health concerns, and adhering to treatment as prescribed. This view of engagement clearly applies to patients across the continuum of care. Using a sample of patients lost to follow up at two urban hospitals, we also explored how information from such assessments could be used as part of clinical interventions to promote engagement, particularly as it relates to treatment initiation and adherence. To our knowledge, there has been only one other study to date that has examined implicit processes among patients undergoing ART [22]. That investigation, however, did not focus on patients with histories of poor engagement or adherence below optimal levels. Only patients who had been reported as lost to follow up for care were targeted for the present study, thus providing information relevant to growing public health efforts aimed at linking individuals to treatment following an HIV diagnosis and retaining them in care.

\section{METHOD}

\section{Participants}

Study participants consisted of 33 patients diagnosed with HIV who were recruited from two large Chicago hospitals. The hospitals, which provide services to a predominantly ethnic minority population with low socioeconomic status, are located in two separate geographic areas of the city with high HIV prevalence rates. A participant was eligible for the study if he or she was 16 years or older, HIV seropositive, and had missed more than half of all scheduled appointments with a medical provider during the past year. Eligible participants were identified by case managers and health care workers at both hospitals from lists of patients who had been identified as lost to follow up.

\section{Procedure}

A posttest-only randomized controlled design was used. Participants were randomly assigned to either the 
assessment or a control group. All procedures for recruitment, data collection and confidentiality were reviewed and approved by the Institutional Review Boards of Mercy Hospital and Medical Center and Mount Sinai Hospital Medical Center in Chicago.

Participants met with a trained interviewer at one of the two hospital sites where the study was conducted. After providing informed consent, participants in both groups were asked to complete measures designed to obtain demographic and adherence information. Assessment group participants were then asked to provide short phrases or sentences describing their thoughts about following their treatment regimen. In cases where participants had not initiated treatment, they were asked to provide statements that described what they believed they would be doing if they were on a regimen. Participants were encouraged to provide a range of treatment-related thoughts, including those involving descriptions of treatment that were abstract (i.e., related to the purpose or possible consequences of their regimen) as well as those that were concrete (i.e., describing the steps required to follow their regimen).

After the elicitation procedure, participants used a laptop computer to access the web-based assessment program which required that they compare each of their thoughts to one another as well as seven phrases used in this study to evaluate each participant's appraisals of treatment. The appraisal phrases were designed to gauge how a patient's own thoughts or descriptions of treatment were related to: (a) intrinsic versus extrinsic motivation (i.e., "something I choose to do in order to get what I really want out of life" versus "something I do because it is required of me or someone else wants me to do it"); (b) approach versus avoidance behavior (“...makes me want to stick with my HIV treatment plan" versus “...makes me want to avoid my HIV treatment plan”); and (c) positive versus negative valence ("something that is positive or pleasant to me" versus "something that is negative or unpleasant to me"). Finally, to determine the extent to which participants viewed a given thought or appraisal as representing their typical views of treatment, they also rated the similarity of each thought and appraisal statement to a self-referent stimulus item ("...describes the way I usually think about my HIV treatment plan").

Participants rated, in quick succession, the similarity of all semantic items to one another using a seven-point rating scale ranging from not at all similar (1) to very similar (7). The web-based assessment program presented all possible paired combinations of semantic items in random order. This paired comparison procedure is consistent with other research assessing implicit cognitive processes [20, 23, 24]. After completion of the paired comparison procedure, a map was generated by MDS that depicted how an individual participant's treatment-related cognitions were associated with treatment appraisals and behaviors.

The interviewer explained the mapping to each assessment group participant, and then conducted a semi-structured interview to obtain the participant's reactions to his or her mapping and the web-based assessment program.After the interview, participants completed measures of treatment motivation and behavioral change intentions. Control group participants, completed the demographics, treatment adherence, treatment motivation, and behavioral change intentions measures only. All study participants received an incentive for their participation.

\section{Measures}

Descriptive demographics. A brief 13 item questionnaire was used to obtain participants' basic demographic data, including age, ethnicity, education, and income.

Treatment adherence. Self-reported adherence was assessed with the AIDS Clinical Trials Group (ACTG) adherence questionnaire [25]. Participants indicated within a four-day period the number of doses missed for each medication prescribed, the number of days all doses were missed, and how closely the prescription was followed (i.e., according to schedule and special instructions).

Participant reactions. A semi-structured interview was conducted with assessment group participants. In these interviews, participants were asked to provide their views of the assessment procedure and the information provided by their MDS map; whether they had learned anything new about how they think about taking their medications; whether they learned anything from the map that surprised them or was unexpected; how accurately they believed the map portrayed their thought processes; whether the information provided by the map could be helpful to them in changing the way they manage their treatment regimen or make decisions about their healthcare. Interviews averaged 30-45 minutes in length.

Exploratory outcome evaluation measures. To explore the effect of the web-based assessment program on treatment motivation, the study employed the 15-item Treatment Self-Regulation Questionnaire (TSRQ); [26, 27]. The TSRQ provides a standard measure of intrinsic and extrinsic motivation for following treatment. To evaluate the effect of the 
assessment program on treatment behavioral change intentions, asingle-item measure was adapted for use in this study from a scale employed in previous research assessing individual intentions to initiate treatment or improve adherence behaviors within the next six months [28].

\section{Data Analytic Strategy}

Participant ratings of treatment-related items were analysed using SMACOF, a MDS program [29]. Twodimensional configurations were generated for each participant. Configurations had acceptable goodness-of-fit measures, with stress values ranging from 0 to 0.15 .

Participant interviews were audiotaped and reviewed. Each interview was transcribed verbatim for analysis. For the present study, the analysis focused on data regarding the extent to which participants reported being unaware of or surprised by cognitive processes captured by multidimensional scaling. Analyses were also conducted to determine whether participants viewed specific implicit processes as facilitating or impeding care engagement. A computer software program, NVivo, was used for data management and analysis. Exemplary quotes were identified to reflect the extent to which participants viewed their treatment-related cognitions as implicit, accurate, and either facilitative or detrimental to care engagement.

Due to the exploratory nature of the study and the corresponding small sample size, quantitative data analysis focused primarily on descriptive statistics. Independent samples t-tests were used to compare the assessment and control groups on measures of treatment motivation and behavior change intentions. Due to skewed values from these measures, log and inverse transformations were employed to obtain more normal distributions of the data.

\section{RESULTS}

\section{Sample Description}

Thirty-three participants were randomized to either the web-based assessment group $(\mathrm{n}=18)$ or control group ( $\mathrm{n}=$ 15). All participants were African American and $67 \%(\mathrm{n}=22)$ were male. The mean age was 35 years $(\mathrm{SD}=12.5$; range $16-62)$. The majority of participants $(61 \%)$ self-identified as being heterosexual, $36 \%$ as gay or bisexual, and $3 \%$ as "other." Eighty-two percent of participants reported being single, and 58\% had children. While slightly more than half of those enrolled in the study indicated that they continued their education beyond high school $(51.5 \%$; $n=17)$, only two reported receiving a baccalaureate or higher level degree. Eighty-eight percent of the sample had annual incomes below $\$ 20,000$.

The bulk of participants reported that they had initiated ART $(85 \% ; n=28)$. All participants had been identified as lost to follow-up by their health providers prior to enrollment in the study. Mean self-reported adherence during the previous four days was 58\%. Participants indicated that they had kept on the average approximately $38 \%$ of their scheduled medical appointments during the past year, with the majority missing medical appointments for at least six consecutive months. The mean length of time participants reported being diagnosed as HIV seropositive was 8.9 years (range, 5 months -31 years). There were no statistically significant differences between the web-based assessment and control groups.

\section{Web-based Assessment: Treatment-related Cognitions}

The number of distinct treatment-related cognitions reported by each participant during the elicitation procedure ranged from 10 to 16. These cognitions included concrete descriptions of ART (e.g., "swallowing a pill") as well as abstract perceptions related to both the purpose and possible consequences of treatment-related behaviors (e.g., "staying alive," "improving my immune system," "having diarrhea"). Some participants provided treatment-related cognitions related to stigma, expressing concerns that others would learn of their serostatus (e.g., "something I have to hide"). Participants used the web-based assessment program to compare all possible paired combinations of their treatmentrelated cognitions, appraisal phrases, and the self-referent stimulus item. Participants compared a mean of 188 paired combinations $(S D=39$; range 137 to 253 ), which were presented successively in random order. All 18 assessment group participants completed the paired comparisons procedure within 45 minutes to an hour.

\section{Participant Reactions}

According to the interview transcripts, the majority of assessment group participants mentioned that the web-based program revealed cognitive processes of which they had been unaware or had underestimated $(72 \%$; $n=13)$. Several 
participants mentioned that they were surprised about the extent of their negative appraisals of treatment (39\%; $n=7)$. One participant, a man in his early 20 s who was prescribed ART slightly more than two years ago, indicated that he was not aware of the extent to which his thoughts about medication side effects (e.g., unpleasant dreams) affected his avoidance of treatment. In addition, he was surprised to learn that thoughts about his family made him want to improve his adherence.

I didn't realize that the dreams and trying to avoid different things [were] half the reason why I don't want to take [the medication]. I didn't realize that. Honestly, I didn't realize that I think so much more about my family than I think about myself. ...It seems like I care more about hurting them than hurting myself.

In general, participants indicated that the visual mappings generated by multidimensional scaling aided them in understanding how underlying cognitive processes affected their treatment behavior. One participant, a woman in her late 20s who had been diagnosed as HIV seropositive slightly more than two years ago, described her reaction upon reviewing her map: "To see it is to believe it. To see actually some of the thoughts that you have in your head, uh, like sitting in front [of you] was very helpful. It was like an eye opener." The view was echoed by another participant, a man in his early 40s who had been diagnosed for 20 years: "Just to see it visually versus thinking it... it was just kind of to me like, 'okay. I understand'.

All assessment group participants reported that they viewed the MDS mappings as accurate representations of their thought processes. In addition, participants tended to describe the mappings as understandable and useful, providing them with ideas about how to better manage their regimens. One third of assessment group participants asked for copies of their maps to remind them of their strengths and weaknesses and to serve as guides to aid in treatment management. When asked about the negative aspects of the web-based assessment program, three participants complained about the tedious nature of the paired-comparison procedure as well as the amount of time required to complete the paired comparisons.

\section{Cognitive Mapping for an Individual Patient: "It Made Me More Aware"}

Table 1 lists treatment-related cognitions generated by an individual participant. This 50 year-old woman had been diagnosed as HIV seropositive for nearly two years prior to her enrollment in the study. She had been identified as lost to follow-up during the past 12 months and reported 75\% adherence in the previous four days. The first 13 cognitions listed in Table 1 were generated by the participant during the elicitation procedure. As noted above, the final seven phrases (i.e., six appraisals and one self-referent statement) were supplied by the assessment program to aid in the interpretation of participant maps.

Table 1. Descriptions of treatment: Cognitions and appraisals for individual participant.

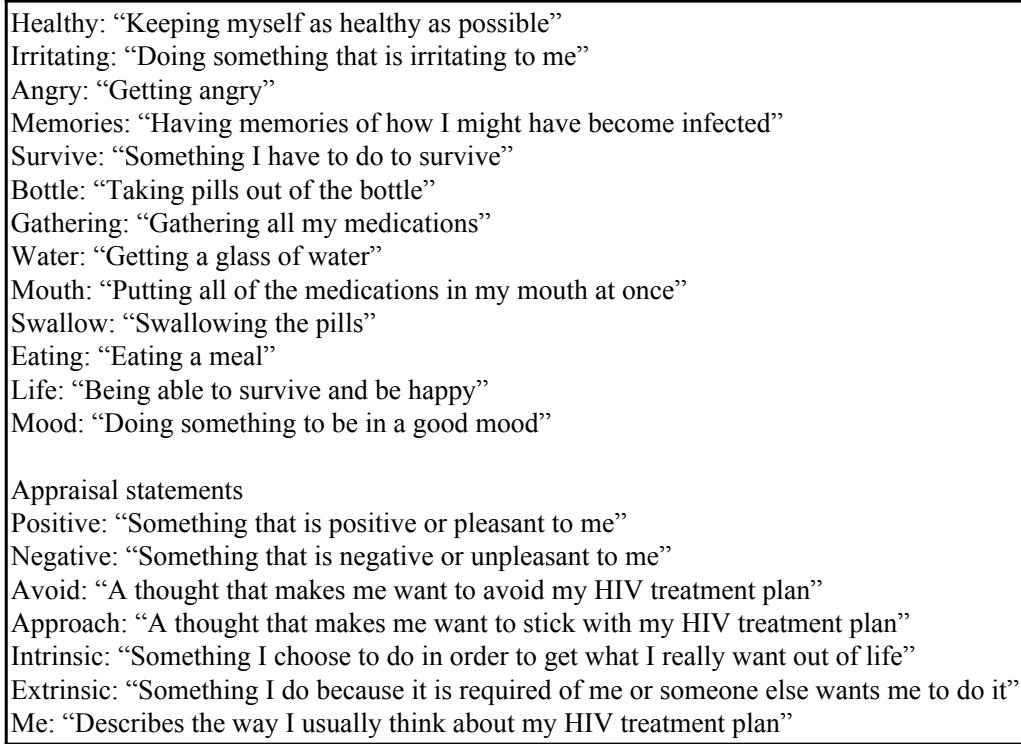

An abbreviation of each of the cognitions and appraisals listed in Table $\mathbf{1}$ appears in the MDS map shown in Fig (1). The proximity of items on the map to one another indicates the degree to which the participant rated them as similar. The left side of the participant's mapping depicts clusters of cognitions (such as "memories" and "irritating") which 
were associated with treatment avoidance and negatively-valenced reactions, due to their proximity to these appraisal statements. Similarly, the right side of the map contains cognitions (e.g., "survival," "life") that were associated with treatment approach-oriented behaviors, intrinsic motivation, and positively-valenced reactions. Items such as "bottle," and "swallow" were equidistant from specific appraisal statements (e.g., "positive," "negative"), suggesting that the participant perceived these cognitions as having mixed valence.

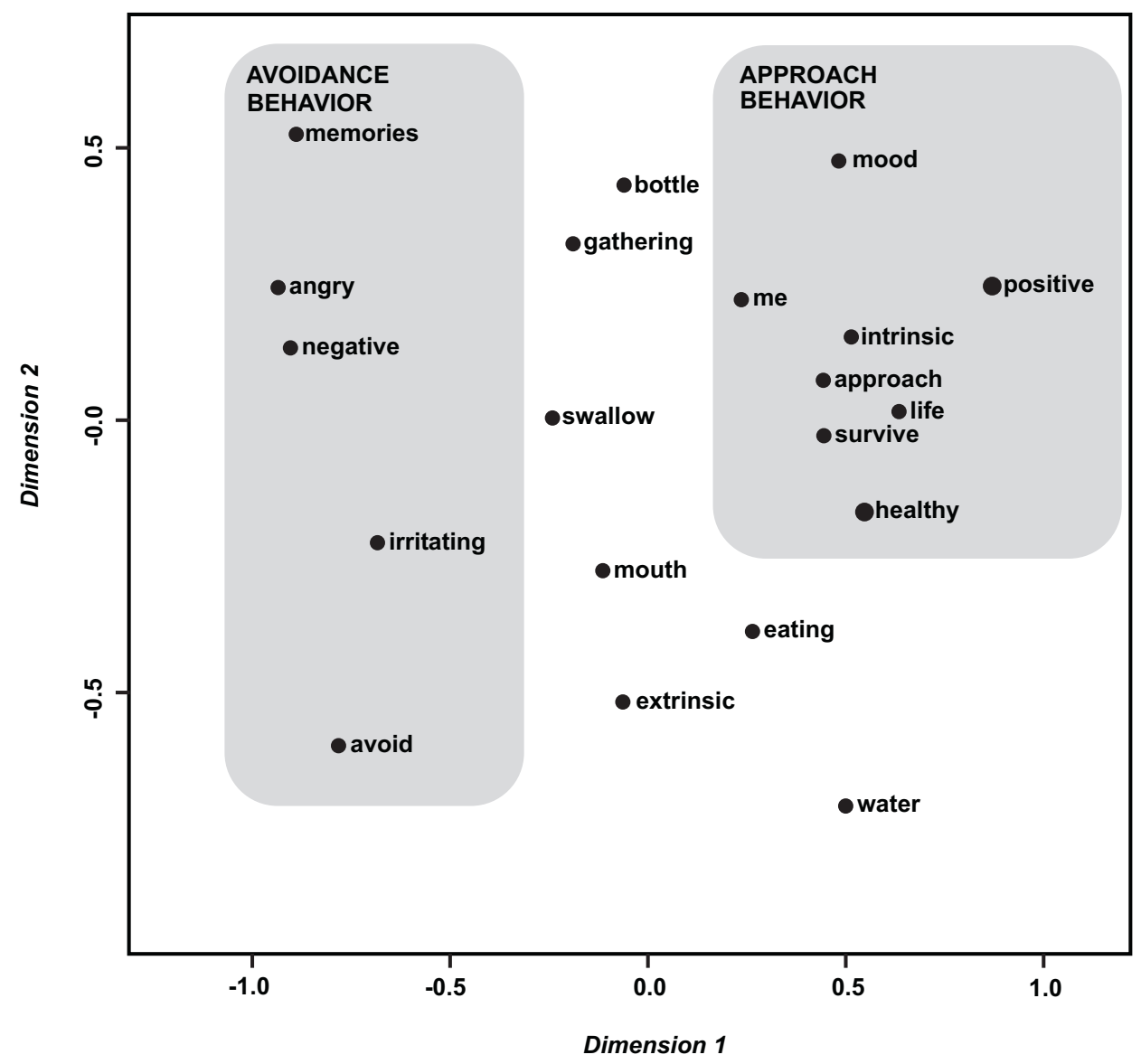

Fig. (1). MDS mapping of treatment-related cognitions and appraisals for individual participant.

A possible interpretation of this participant's mapping is that she avoids treatment when she associates it with painful thoughts of how she became infected during a previous relationship (e.g., "memories"), and is more likely to follow her regimen when thinking of it in terms of its health promoting effects (e.g., something done to "survive and be happy"). In the semi-structured interview, the participant indicated that she had not been aware of the connection between these cognitions and her treatment behaviors prior to the web-based assessment:

The process of doing this [made me] knowledgeable of myself and some of the things I wasn't knowing all the time came out ... it let's me know what areas I really need to work on... [I]t made me aware of how much of the negative I feel... Sometimes I get angry and sometimes I have flashbacks.

The visual display of her thoughts and their connection to treatment provided her with clues about how to improve her adherence:

I will probably change getting angry and thinking negative because I get angry a lot. And like I said, I never got any closure [on the relationship] so that's why my memories [are there]. I've tried everything to get the truth and I guess that's why it's so high on the chart.

Like others in this study who expressed concerns about stigma and reluctance in sharing personal information, the participant indicated that she felt more comfortable revealing her private cognitive processes through the web-based program than she would have with another individual, including health providers and family members.

You know like your family members, they can be judgmental - not wanting to be judgmental. ... Even the 
doctors... sometimes I don't want to be open about certain things. This is the feeling. I feel it [the program] can be very helpful. It can't judge me. It doesn't know me from Adam basically and it doesn't have any history of me.

\section{Exploratory Outcomes: Treatment Behavior Change Intentions and Treatment Motivation}

Results for the effect of the web-based assessment program on behavior change intentions and treatment motivation are shown in Table 2. When asked to indicate their intentions to either improve their adherence or initiate ART within the next six months, assessment group participants reported significantly greater levels of change intentions than those in the control group ( $p=.02$; Cohen's $d=0.84$ ). Based on a median split, the proportion of assessment group participants who reported high levels of change intentions relative to control group participants was $83 \%$ versus $47 \%$. There were no statistically significant differences between the two groups of participants with regard to either intrinsic or extrinsic treatment motivation.

Table 2. Treatment behavioral change intentions and treatment motivation.

\begin{tabular}{|c|c|c|c|c|c|}
\hline Measure & $\begin{array}{c}\text { Sample } \\
(\mathbf{n}=\mathbf{3 3})\end{array}$ & $\begin{array}{c}\text { Assessment } \\
(\mathbf{n = 1 8})\end{array}$ & $\begin{array}{c}\text { Control } \\
(\mathbf{n = 1 5})\end{array}$ & Test Statistic & $\boldsymbol{P}^{*}$ \\
\hline Change intentions & $8.7(2.4)$ & $9.6(1.3)$ & $7.6(3.1)$ & 2.44 & 0.02 \\
\hline Intrinsic motivation & $6.6(0.8)$ & $6.7(0.6)$ & $6.4(0.9)$ & 0.81 & 0.43 \\
\hline Extrinsic motivation & $4.2(0.8)$ & $4.1(1.4)$ & $4.2(1.6)$ & -0.13 & 0.90 \\
\hline
\end{tabular}

$* p<.05$

Note. The $\mathrm{p}$ values are values on independent samples t-tests. Motivation and change intention scores were transformed before conducting statistical tests to account for skewed distributions. Mean values are presented in original units.

\section{DISCUSSION}

This study is the first to explore how the assessment of implicit cognitive processes could be used to improve care engagement among patients identified as lost to follow up for HIV care. The study builds on a growing body of research that focuses on the active role played by implicit cognitive processes in health behaviors [2, 30 - 32]. Participants in this investigation often stated that they had been unaware of how various cognitions and associations influenced their disengagement from care or avoidance of treatment. Similarly, participants also indicated that they had been unaware of cognitive processes that prompted behaviors favorable to treatment adherence, appointment keeping, and active communication with health providers.

Linking individuals to treatment following an HIV diagnosis and retaining them in care is part of a public health strategy that utilizes antiretroviral medications to reduce the viral load of people living with HIV, thereby limiting onward transmission [33 - 39]. Findings from the present study suggest that MDS-based assessments of implicit cognitive processes have potential value in clinical interventions aimed at retaining patients and strengthening their engagement with care. Participants who received MDS-based assessments reported significantly greater intentions to initiate treatment or improve the adherence behaviors than control group participants within the next six months. Findings suggest that the patient-specific information provided by MDS maps could be used to devise clinical interventions tailored to the individual. As occurred during this study, such interventions should encourage patients to discuss their maps with close attention to how various thoughts affect their health-related behavior.

This preliminary study has limitations that should be noted. First, it used a cross-sectional design which consequently prevented a direct evaluation of the effect of the web-based assessment approach on adherence and appointment keeping. Future research should build on the promising initial results of this investigation by employing longitudinal designs. Secondly, given the small sample size, the study may be limited in its ability to generalize to a larger population of PLH lost to follow up, particularly those who have never initiated ART. These limitations notwithstanding, the results indicate that a web-based assessment program using multidimensional scaling provides useful information on implicit cognitive processes and can be a viable tool in efforts to engage lost to follow up patients.

The mappings produced via MDS visually depict implicit cognitions that both compromise and facilitate adherence. For this reason, MDS mappings could aid patients in learning to think strategically about treatment. For example, cognitive processes revealed by mappings that are related to treatment avoidance could be addressed by developing "ifthen" implementation intentions [2]. An individual patient might use cognitive items to develop a personalized if-then plan geared toward improving their adherence goal: "If I find myself thinking about how I became infected with HIV, 
then I will direct all my energy and attention to thinking about staying healthy for my children." The first part of the statement represents an avoidance-oriented cognition whereas the second part contains an approach-oriented one. Based on other research using implementation intentions, it is reasonable to assume that implementation intentions derived from the MDS maps would resonate strongly with patients given that they reflect thoughts that the patient actually experiences. With practice, if-then statements could help weaken the strength of avoidance-oriented cognitions. To bolster the impact of these statements, patients could be encouraged to share their implementation intentions with a source of autonomy support, such as a health provider, therapist, or significant other. If devised before a patient begins a regimen, implementation intentions could aid in addressing potential treatment hurdles as well as capitalizing on hidden cognitive resources.

Interventions based on MDS maps could also be developed to promote patient motivation. The technique may help fill an unmet need among health providers with less training in motivational interviewing or other clinical approaches that involve exploring how underlying psychological processes may influence a patient's treatment behavior. The maps could aid clinicians in helping patients weigh the pros and cons of behavior change, thereby stimulating change intentions. MDS maps could even be used to generate personally-meaningful "primes," which could, for example, be transmitted to patient cell phones to improve adherence or care engagement (e.g., medication dosage reminders, cues for appointment keeping with health providers).

Finally, MDS maps could be used as part of interventions designed to build mindfulness, an individual characteristic that may help patients to disengage from implicit processes, such as those that compromise treatment behaviors [1]. Research indicates that individuals with low levels of mindfulness are more susceptible to the influence of healthcompromising implicit processes [1, 40]. Through a combination of MDS assessment and mindfulness meditation training, patients could increase their awareness of specific fleeting cognitive processes that have been identified through MDS, and develop skills to regulate them in the here and now.

\section{CONFLICT OF INTEREST}

The authors confirm that this article content has no conflict of interest.

\section{ACKNOWLEDGEMENTS}

This research was supported by a grant from the Educational and Research Initiative Fund (ERIF).

\section{REFERENCES}

[1] Levesque C, Copeland K, Sutcliffe R. Conscious and nonconscious processes: Implications for self-determination theory. Can Psychol 2008; 49(3): 218-24.

[http://dx.doi.org/10.1037/a0012756]

[2] Sheeran P, Gollwitzer PM, Bargh JA. Nonconscious processes and health. Health Psychol 2013; 32(5): 460-73. [http://dx.doi.org/10.1037/a0029203] [PMID: 22888816]

[3] Houston E, McKirnan D, Cervone D, Johnson MS, Sandfort TGM. Assessing treatment motivation among patients receiving antiretroviral therapy: A multidimensional approach. Psychol Health 2011; 27(6): 674-87.

[4] Cargill VA, Stone VE, Robinson MR. HIV treatment in African Americans: Challenges and opportunities. J Black Psychol 2004; 30(1): 24-39.

[http://dx.doi.org/10.1177/0095798403259243]

[5] Fagbami O, Oluwasanjo A, Fitzpatrick C, Fairchild R, Shin A, Donato A. Factors supporting and inhibiting adherence to HIV medication regimen in women: A qualitative analysis of patient interviews. Open AIDS J 2015; 9: 45-50. [http://dx.doi.org/10.2174/1874613601509010045] [PMID: 26157537]

[6] Orlando M, Burnam MA, Beckman R, et al. Re-estimating the prevalence of psychiatric disorders in a nationally representative sample of persons receiving care for HIV: results from the HIV cost and services utilization study. Int J Methods Psychiatr Res 2002; 11(2): 75-82. [http://dx.doi.org/10.1002/mpr.125] [PMID: 12459797]

[7] Thrasher AD, Earp JA, Golin CE, Zimmer CR. Discrimination, distrust, and racial/ethnic disparities in antiretroviral therapy adherence among a national sample of HIV-infected patients. J Acquir Immune Defic Syndr 2008; 49(1): 84-93. [http://dx.doi.org/10.1097/QAI.0b013e3181845589] [PMID: 18667919]

[8] Wagner GJ, Goggin K, Remien RH, et al. A closer look at depression and its relationship to HIV antiretroviral adherence. Ann Behav Med 2011; 42(3): 352-60.

[http://dx.doi.org/10.1007/s12160-011-9295-8] [PMID: 21818528]

[9] Bongers KC, Dijksterhuis A. Consciousness as a trouble shooting device? The role of consciousness in goal-pursuit. In: Morsella E, Bargh JA, Gollwitzer P, Eds. The Oxford Handbook of Human Action. New York: Oxford University Press Inc. 2009; pp. 589-604. 
[10] Phillips WJ, Hine DW, Thorsteinsson EB. Implicit cognition and depression: a meta-analysis. Clin Psychol Rev 2010; $30(6)$ : 691-709. [http://dx.doi.org/10.1016/j.cpr.2010.05.002] [PMID: 20538393]

[11] Beck JS. Cognitive therapy: Basics and beyond. New York, NY: Guilford Press 1995.

[12] Bartlett JA. Addressing the challenges of adherence. J Acquir Immune Defic Syndr 2002; 29(Suppl. 1): S2-10. [http://dx.doi.org/10.1097/00126334-200202011-00002] [PMID: 11832696]

[13] Chesney MA, Farmer P, Leandre F, Malow R, Starace F. Human immunodeficiency virus and acquired immunodeficiency syndrome. In: Sabate E, Ed. Adherence to long-term therapies: Evidence for action. Geneva, Switzerland: World Health Organization 2003 ; pp. 95-106. [accessed 7.5.15]

[14] Beer L, Heffelfinger J, Frazier E, et al. Use of and adherence to antiretroviral therapy in a large U.S. sample of HIV-infected adults in care, 2007-2008. Open AIDS J 2012; 6: 213-23. [http://dx.doi.org/10.2174/1874613601206010213] [PMID: 23056163]

[15] de Bruin M, Viechtbauer W, Schaalma HP, Kok G, Abraham C, Hospers HJ. Standard care impact on effects of highly active antiretroviral therapy adherence interventions: A meta-analysis of randomized controlled trials. Arch Intern Med 2010; 170(3): 240-50. [http://dx.doi.org/10.1001/archinternmed.2009.536] [PMID: 20142568]

[16] Nosek BA, Hawkins CB, Frazier RS. Implicit social cognition: from measures to mechanisms. Trends Cogn Sci (Regul Ed) 2011; 15(4): 152-9. [http://dx.doi.org/10.1016/j.tics.2011.01.005] [PMID: 21376657]

[17] Greenwald AG, Banaji MR. Implicit social cognition: attitudes, self-esteem, and stereotypes. Psychol Rev 1995; $102(1)$ : 4-27. [http://dx.doi.org/10.1037/0033-295X.102.1.4] [PMID: 7878162]

[18] Kruskal JB, Wish M. Multidimensional scaling. Beverly Hills, CA: Sage 1978.

[19] Stalans LJ. Multidimensional scaling. In: Grimm LG, Yarnold PR, Eds. Reading and understanding multivariate statistics. Washington, D.C.: American Psychological Association 1995; pp. 137-68.

[20] Lease AM, McFall RM, Treat TA, Viken RJ. Assessing children's representations of their peer group using a multidimensional scaling technique. J Soc Pers Relat 2003; 20: 707-28. [http://dx.doi.org/10.1177/0265407503206001]

[21] Jones LE, Koehly LM. Multidimensional scaling. In: Keren G, Lewis C, Eds. A handbook for data analysis in the behavioral sciences: Methodological issues. Hillsdale, NJ: Erlbaum 1993; pp. 95-164.

[22] Jones G, Hawkins K, Mullin R, et al. Understanding how adherence goals promote adherence behaviours: a repeated measure observational study with HIV seropositive patients. BMC Public Health 2012; 12: 587. [http://dx.doi.org/10.1186/1471-2458-12-587] [PMID: 22853824]

[23] Cacioppo JT, von Hippel W, Ernst JM. Mapping cognitive structures and processes through verbal content: the thought-listing technique. J Consult Clin Psychol 1997; 65(6): 928-40. [http://dx.doi.org/10.1037/0022-006X.65.6.928] [PMID: 9420354]

[24] Stacy AW, Newcomb MD, Ames SL. Implicit cognition and HIV risk behavior. J Behav Med 2000; 23(5): $475-99$. [http://dx.doi.org/10.1023/A:1005577132666] [PMID: 11039159]

[25] Chesney MA, Ickovics JR, Chambers DB, et al. Self-reported adherence to antiretroviral medications among participants in HIV clinical trials: The AACTC adherence instruments. AIDS Care 2000; 23(3): 255-66. [http://dx.doi.org/10.1080/09540120050042891] [PMID: 10928201]

[26] Williams GC, Freedman Z, Deci EL. Promoting motivation for diabetics's self-regulation of HbA1c. Diabetes 1996; 45(Suppl. 2): 13A.

[27] Williams GC, Rodin GC, Ryan RM, Grolnick WS, Deci EL. Autonomous regulation and long-term medication adherence in adult outpatients. Health Psychol 1998; 17(3): 269-76. [http://dx.doi.org/10.1037/0278-6133.17.3.269] [PMID: 9619477]

[28] Willey C, Redding C, Stafford J, et al. Stages of change for adherence with medication regimens for chronic disease: development and validation of a measure. Clin Ther 2000; 22(7): 858-71. [http://dx.doi.org/10.1016/S0149-2918(00)80058-2] [PMID: 10945512]

[29] de Leeuw J, Heiser WJ. Multidimensional scaling with restrictions on the configuration. In: Krishnaiah PR, Ed. Multivariate Analysis. Amsterdam: North-Holland 1980; pp. 501-22.

[30] Aarts H. Health and goal-directed behavior: The nonconscious regulation and motivation of goals and their pursuit. Health Psychol Rev 2007; 1: $53-82$. [http://dx.doi.org/10.1080/17437190701485852]

[31] Dijksterhuis A, Aarts H. Control, consciousness, and agency. In: Aarts H, Elliott AJ, Eds. Goal-directed behavior. New York: Psychology Press 2012; pp. 301-23.

[32] Ferguson MJ, Hassin R, Bargh JA. Implicit motivation: Past, present, and future. In: Shah J, Gardner W, Eds. Handbook of motivation science. New York: Guilford 2008; pp. 150-68.

[33] Das M, Chu PL, Santos G-M, et al. Decreases in community viral load are accompanied by reductions in new HIV infections in San 
Francisco. PLoS One 2010; 5(6): e11068.

[http://dx.doi.org/10.1371/journal.pone.0011068] [PMID: 20548786]

[34] Dieffenbach CW, Fauci AS. Universal voluntary testing and treatment for prevention of HIV transmission. JAMA 2009; 301(22): 2380-2. [http://dx.doi.org/10.1001/jama.2009.828] [PMID: 19509386]

[35] Granich RM, Gilks CF, Dye C, De Cock KM, Williams BG. Universal voluntary HIV testing with immediate antiretroviral therapy as a strategy for elimination of HIV transmission: a mathematical model. Lancet 2009; 373(9657): 48-57. [http://dx.doi.org/10.1016/S0140-6736(08)61697-9] [PMID: 19038438]

[36] Metsch LR, Pereyra M, Messinger S, et al. HIV transmission risk behaviors among HIV-infected persons who are successfully linked to care. Clin Infect Dis 2008; 47(4): 577-84 [http://dx.doi.org/10.1086/590153] [PMID: 18624629]

[37] Montaner JS, Lima VD, Barrios R, et al. Association of highly active antiretroviral therapy coverage, population viral load, and yearly new HIV diagnoses in British Columbia, Canada: a population-based study. Lancet 2010; 376(9740): 532-9. [http://dx.doi.org/10.1016/S0140-6736(10)60936-1] [PMID: 20638713]

[38] Office of National AIDS Policy (ONAP). National HIV/AIDS strategy for the United States; 2010, Available at: http://www.whitehouse.gov/sites/default/files/uploads/NHAS.pdf. [accessed 12.5.14];

[39] Padian NS, McCoy SI, Karim SS, et al. HIV prevention transformed: the new prevention research agenda. Lancet 2011; 378(9787): 269-78. [http://dx.doi.org/10.1016/S0140-6736(11)60877-5] [PMID: 21763938]

[40] Brown KW, Ryan RM. The benefits of being present: mindfulness and its role in psychological well-being. J Pers Soc Psychol 2003; 84(4): $822-48$

[http://dx.doi.org/10.1037/0022-3514.84.4.822] [PMID: 12703651]

(C) Houston et al. Licensee Bentham Open.

This is an open access article licensed under the terms of the Creative Commons Attribution-Non-Commercial 4.0 International Public License (CC BY-NC 4.0) (https://creativecommons.org/licenses/by-nc/4.0/legalcode), which permits unrestricted, non-commercial use, distribution and reproduction in any medium, provided the work is properly cited. 